\title{
The Efflux Transport of Choline through Blood-Brain Barrier is Inhibited by Alzheimer's Disease Therapeutics
}

\author{
Na-Young LeE and Young-Sook KanG* \\ College of Pharmacy and Research Institute of Pharmaceutical Sciences, Sookmyung Women's University, Seoul, Korea
}

(Received June 17, 2008; Revised July 8, 2008; Accepted July 16, 2008)

\begin{abstract}
In the present study, we examined the effects of several therapeutics of Alzheimer's disease, such as donepezil hydrochloride, tacrine and $\alpha$-phenyl-n-tert-butyl nitrone (PBN) on choline efflux from brain to circulating blood. The brain-to-blood efflux of $\left[{ }^{3} \mathrm{H}\right]$ choline in rats was significantly inhibited by tacrine and PBN. Also the $\left[{ }^{3} \mathrm{H}\right]$ choline efflux was reduced by tacrine and donepezil hydrochloride in the TR-BBB cells, in vitro the blood-brain barrier (BBB) model. These results suggest that these drugs may influence choline efflux transport from brain to blood and regulate the choline level in brain resulting in the increase of acetylcholine synthesis.
\end{abstract}

Keywords: Blood-brain barrier, Choline transport, Alzheimer's disease therapeutics, in vivo brain efflux index method, TR-BBB cells

\section{INTRODUCTION}

The blood-brain barrier (BBB) is comprised by tight junctions of the brain capillary endothelial cells, which are highly restrictive for the entry of drugs used in the treatment of CNS disorder from the blood to the brain parenchyma cells (Cornford, 1985; Pardridge, 1988). Actually, many clinical developments of CNS-acting drugs have to be stopped because of poor permeability across the BBB (Ohtsuki and Terasaki, 2007). In the brain, various transporters exist on the endothelial cell membrane and carry out the transport of specific endogenous compounds as well as many pharmacological agents to the brain (Spector, 1989). For example, L-DOPA, delivered into the brain through the amino acid transporter at the BBB, showed the therapeutic effect at Parkinson's disease in the brain (Smith, 1993). Similarly, the BBB choline transporter has been proposed as a drug delivery vectors for various amine compounds. Basic amine drug, eperisone, competitively inhibited choline uptake in rats (Kang et al., 1990), and the derivatives of lobeline and isoarecolone could enter into the brain via the BBB choline transporter (Metting et al., 1998). Therefore, it is necessary to understand the relationship between various transporters and CNS drugs at the BBB, and this knowledge can be

\footnotetext{
${ }^{*}$ Corresponding author

Tel: +82-2-710-9562, Fax: +82-2-2077-7975

E-mail: yskang@sm.ac.kr
}

applied to clinical development of CNS drugs.

Tacrine is the first drug approved specifically for the treatment of Alzheimer's disease (AD). It has amino acridine ring, and was proved to improve memory, language, praxis and activities of daily life (Grason, 1996; Knapp et al., 1994). Donepezil hydrochloride is a piperidine-based reversible cholinesterase inhibitor that exhibits high specificity for centrally active acetylcholinesterase approved the treatment of AD (Rho and Lipson, 1997). In addition, $\alpha$-phenyl- $n$-tert-butyl nitrone (PBN), a nitronebased spin trapping agent has been proposed as a therapeutic agent for stroke (Knecht and Mason, 1993; Zhao et al., 1994). The brain distribution of these drugs was relatively high (MaNally et al., 1996; Matsui et al., 1999), but the transport mechanism has not yet been known. Especially, cholinesterase inhibitors such as tacrine and donepezil hydrochloride represent the standard therapeutic approach for the treatment of $A D$, and acetylcholine level in the brain has been considered to be one of important thesis as maintaining the brain function. Choline is a precursor of acetylcholine, which has to be supplied from blood circulation through the choline transporter at the BBB to maintain brain acetylcholine level, because it is synthesized minimally in the brain (Blusztajn and Wurtman, 1983; Wurtman, 1992). In the previous study, we found that tacrine, donepezil hydrochlolide and PBN inhibited choline uptake at the BBB suggesting the possibility of these drugs being transported into the brain through the choline transporter (Kang et al., 2005). Our 
study concerns the effects of tacrine, donepezil hydrochloride, and PBN on choline efflux to understand more about the relationship between choline transporter and these drugs used for the treatment of $A D$ or stroke.

\section{MATERIALS AND METHODS}

\section{Materials}

[Methlyl- $\left.{ }^{3} \mathrm{H}\right]$ Choline $\left({ }^{3} \mathrm{H}\right]$ choline, $\left.86.0 \mathrm{Ci} / \mathrm{mmol}\right)$ and [carboxyl $-{ }^{14} \mathrm{C}$ ]inulin $\left(\left[{ }^{14} \mathrm{C}\right]\right.$ inulin, $\left.1.92 \mathrm{mCi} / \mathrm{g}\right)$ was purchased from NEN Life Sciences (Boston, MA, USA). $\alpha$ Phenyl-n-tert-butyl-nitrone (PBN) was obtained from Aldrich Chemical Co. (Milwaukee, Wisconsin, USA). Tacrine, 9-amino-1, 2, 3, 4-tetrahydroacridine hydrochloride, was provided from Jeil Co. (Seoul, Korea). Donepezil hydrochloride, ( \pm -2-[(1-benzylpiperidin-4-yl) methyl]-5, 6dimethoxyindan-1-one monohydrochloride, was provided from Daewoong Co. (Seoul, Korea). Ketamine hydrochloride was obtained under help from Yuhan Co. (Seoul, Korea) used an anesthetics. Hionic-fluor and Soluene350 were purchased from Packard Instruments (Meriden, CT, USA). All other chemicals were of reagent grade and available commercially.

\section{Brain efflux index (BEI) study}

In vivo brain efflux experiments were performed as described previously (Kakee et al., 1996). Male SpragueDawley rats (Samtaco, Osan, Korea) weighing 230-270 g were anesthetized with an intramuscular injection of a mixture of ketamine $(100 \mathrm{mg} / \mathrm{kg})$ and xylazine $(2 \mathrm{mg} / \mathrm{kg})$ and their heads were fixed in a stereotaxic frame (Stoelting Co., Wood Dale, IL, USA). After exposing the skull, a $1.0 \mathrm{~mm}$ hole was made in the skull, $0.20 \mathrm{~mm}$ anterior and $5.5 \mathrm{~mm}$ lateral to the bregma using a dental drill (Eicom Co., Tokyo, Japan). Then, a $0.50 \mu \mathrm{L}$ of an extracellular fluid (ECF) buffer containing $\left[{ }^{3} \mathrm{H}\right]$ choline $(80 \mathrm{nCi})$ and $\left[{ }^{14} \mathrm{C}\right]$ inulin $(4 \mathrm{nCi})$ in the presence or absence of drugs was administered to rat brain over $1 \mathrm{~min}$ via a $5.0 \mu \mathrm{L}$ microsyringe (Hamilton, Reno, NE, USA) fitted with a needle $(100 \mu \mathrm{m}$ i.d., $350 \mu \mathrm{m}$ o.d.; Natsume, Tokyo, Japan) which was inserted into the Par2 region through a hole to a depth of $4.5 \mathrm{~mm}$. The ECF buffer (pH 7.4) was composed of $122 \mathrm{mM} \mathrm{NaCl}, 25 \mathrm{mM} \mathrm{NaHCO}_{3}, 10 \mathrm{mM} \mathrm{D}$ glucose, $3 \mathrm{mM} \mathrm{KCl}, 1.4 \mathrm{mM} \mathrm{CaCl}, 1.2 \mathrm{mM} \mathrm{MgSO}_{4}, 0.4$ $\mathrm{mM} \mathrm{K} \mathrm{HPO}_{4}$, and $10 \mathrm{mM} \mathrm{HEPES}$. At appropriate time, the brain was removed, and ipsilateral (left) cerebrum was isolated. After weighing each of these, tissue samples were dissolved in $3.0 \mathrm{~mL}$ of Soluene- 350 at $60^{\circ} \mathrm{C}$ for $3 \mathrm{~h}$, and then mixed with $10 \mathrm{~mL}$ hionic-fluor. The associated radioactivity was determined in a liquid scintillation counter (LSC 6500, Beckman, Fullerton, CA, USA) with the automatic external standard for quenching correction.

The BEI was defined by equation (1) and the percentage of substrate remaining in the ipsilateral cerebrum was determined using equation (2) (Kakee et al., 1996).

$$
\begin{aligned}
& \mathrm{BEI}(\%)=\frac{\text { Amount of test substrate effluxed at the BBB }}{\text { Amount of test substrate injected into the brain }} \times 100 \\
& 100-\mathrm{BEI}(\%)=\frac{\left(\begin{array}{c}
\text { Amount of test substrate in brain } \\
\overline{\text { Amount of reference in brain }}
\end{array}\right)}{\left(\begin{array}{c}
\text { Concentration of test substrate injected } \\
\overline{\text { Concentration of reference injected }}
\end{array}\right)} \times 100
\end{aligned}
$$

\section{Cell culture}

TR-BBB cells were grown routinely in collagen type-I coated tissue culture dishes (Iwaki Co., Chiba, Japan) at $33^{\circ} \mathrm{C}$ under $5 \% \mathrm{CO}_{2}$ and $95 \%$ air as described previously (Hosoya et al., 2000). These cells were cultured in Dulbecco's modified Eagle's medium (GIBCO, Grand Island, NY, USA) supplemented with penicillin-streptomycin (GIBCO, NY, USA), 10\% fetal bovine serum (GIBCO, Grand Island, NY, USA) and $15 \mu \mathrm{g} / \mathrm{L}$ endothelial cell growth factor (Roche, Mannheim, Germany).

\section{Measurements of $\left[{ }^{3} \mathrm{H}\right]$ choline efflux in TR-BBB cells}

After cell culture, which is the same as uptake experiment, ECF buffer containing $0.5 \mu \mathrm{Ci}\left[{ }^{3} \mathrm{H}\right]$ choline and 0.1 $\mu \mathrm{Ci}\left[{ }^{14} \mathrm{C}\right]$ inulin was added to the TR-BBB cells, followed by the incubation for $60 \mathrm{~min}$ at $37^{\circ} \mathrm{C}$. After $60 \mathrm{~min}$ incubation, the applied solution was removed from the cells, followed by the addition of ice-cold ECF buffer. Then, the ECF buffer at $37^{\circ} \mathrm{C}$ in the presence or absence of drugs was added to the cells, followed by the incubation for the desired times. After removal of incubation medium, the cells were solubilized in $1 \mathrm{~N} \mathrm{NaOH}$ for overnight at RT. An aliquot was taken for the measurements of the amount of $\left[{ }^{3} \mathrm{H}\right]$ choline remained in the cells.

\section{Statistical analysis}

Unless otherwise indicated, all data represent the mean \pm SEM. An unpaired, two-tailed Student's t-test was used to determine the significance of differences between two group means. Statistical significance among means of more than two groups was determined by oneway analysis of variance (ANOVA) followed by modified Fisher's least squares difference method and $p<0.05$ was considered to be statistically significant.

\section{RESULTS}

To investigate the influence of various drugs on cho- 
line efflux transport at the BBB, several drugs were coadministered with $\left[{ }^{3} \mathrm{H}\right]$ choline into the rat brain and their inhibitory effects in the choline efflux transport were evaluated (Table I). $\left[{ }^{3} \mathrm{H}\right]$ Choline efflux transport was inhibited more than $90 \%$ by hemicholinum-3, whereas betaine, an inhibitor of GABA transporter had no effect on $\left[{ }^{3} \mathrm{H}\right]$ choline efflux transport. $\left[{ }^{3} \mathrm{H}\right]$ Choline efflux was inhibited about $50 \%$ by verapamil, a substrate and an inhibitor of $p$-glycoprotein. Tacrine and PBN also inhibited $\left[{ }^{3} \mathrm{H}\right]$ choline efflux transport more than $40 \%$ and $50 \%$, respectively. But, $\left[{ }^{3} \mathrm{H}\right]$ choline efflux transport was not significantly inhibited by acetyl L-carnitine. In addition, $\left[{ }^{3} \mathrm{H}\right]$ choline was effluxed by TR-BBB cells, in vitro BBB model. As shown in Fig. 1, the amount of intracellular $\left[{ }^{3} \mathrm{H}\right]$ choline was decreased in a time-dependent manner up to $30 \mathrm{~min}$ in TR-BBB cells. Donepezil hydrochloride and tacrine inhibited $\left[{ }^{3} \mathrm{H}\right]$ choline efflux significantly at 15 and $30 \mathrm{~min}$ (Fig. 1).

\section{DISCUSSION}

It has been performed successfully to the delivery of several drugs to the brain by amino acid transporter at the BBB previously. It was reported that various drugs such as baclofen, melphan, sulfoximine, azaserine, LDOPA and L-NAM (L-2-amino-7-bis[(2-chloroethyl) amino]1,2,3,4-tetrahydro-2-naphthoic acid) were transported into brain through the BBB by large neutral amino acid transporter (Smith, 1993; Takada et al., 1992). In addition, choline transporter at the BBB was used for the delivery of cholinergic and nicotine-like drugs to the brain (Metting et al., 1998). It has been demonstrated that in vivo and in vitro transport of choline into the brain is carriermediated and saturable (Allen and Smith, 2001; Cornford et al., 1978). It was reported that the plasma choline concentration in healthy adults is approximately $10 \mu \mathrm{M}$ (Cohen et al., 1995). This value is less than the calculated $\mathrm{K}_{\mathrm{m}}$ for the BBB choline transporter (about $45 \mu \mathrm{M}$ in vivo, and $20 \mu \mathrm{M}$ in vitro), thus this transporter is not saturated under physiological conditions (Allen and Smith, 2001; Sawada et al., 1999). These characteristics imply that this carrier may deliver therapeutic molecules to the brain (Smith, 1993). In our previous study, we suggested the possibility of various amine drugs, such as tacrine, donepezil hydrochloride and PBN being transported into the brain through the choline transporter at the BBB (Kang et al., 2005). Therefore, in the present study, we evaluated the change of the efflux transport of choline from brain to circulating blood by several therapeutics of $A D$, such as donepezil hydrochloride and tacrine.

We proved that choline undergoes efflux from brain to blood across the BBB via a carrier-mediated efflux transport system for the first time. Choline efflux transport rate at the BBB is similar to blood-to-brain influx rate and this efflux process is saturable (Lee and Kang, 2006). Therefore, this efflux system is supposed to play an important role in the choline turnover in the brain. Our results showed that donepezil hydrochloride, tacrine and PBN inhibited significantly choline efflux at the BBB in vivo and in vitro (Fig. 1 and Table I). Especially, it is interesting that donepezil hydrochloride and tacrine inhibited efflux of choline. In the AD brain, choline uptake to the brain was decreased compared to normal brain and brain choline level in the $A D$ patients was also decreased (Cohen et al., 1995; Nitsch et al., 1992). Furthermore, it has been reported that the decrease of choline level in AD brain may slow down acetylcholine synthesis because $K_{\mathrm{m}}$ of choline acetyltransferase is relatively high $(30-100 \mu \mathrm{M})$ (Blusztajn and Wurtman, 1983). The decrease of acetylcholine synthesis caused by reduction of choline level in the brain led to the cholinergic deficit in AD (Nitsch et al., 1992). Therefore, the increase in the brain choline level can be one of the most effective strategies as an $A D$ therapy leads to an increase of acetylcholine level in the brain. In the previous report, choline was accumulated in the brain slices during the preincubation with tacrine (Dolezal and Tucek, 1992). Dolezal and Tucek proposed that the potency of tacrine to increase the content and

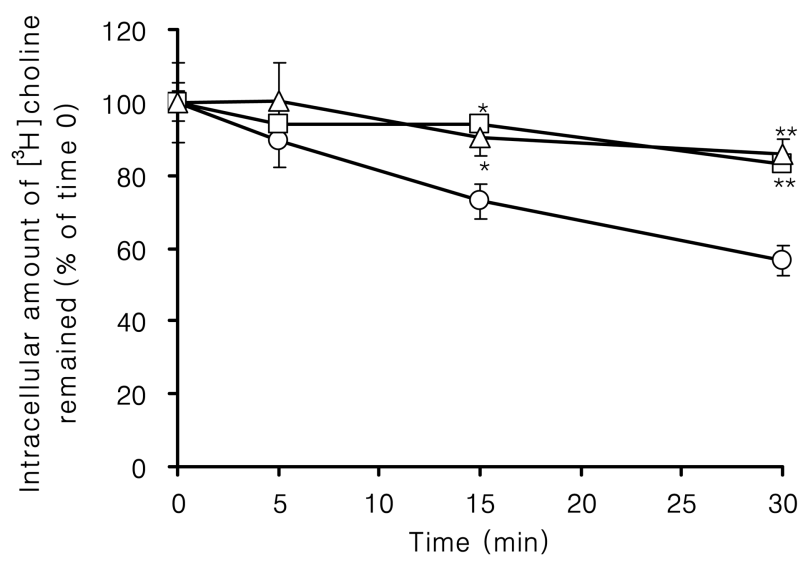

Fig. 1. Time-course of $\left[{ }^{3} \mathrm{H}\right]$ choline efflux in TR-BBB cells. The cells were incubated with ECF buffer containing $\left[{ }^{3} \mathrm{H}\right]$ choline $(11.6 \mathrm{nM})$ for $60 \mathrm{~min}$ at $37^{\circ} \mathrm{C}$. Then, the cells were incubated with ECF buffer in the absence (control, $O$ ) or presence of tacrine $(\triangle)$ or donepezil hydrochloride $(\square)$ for the specified periods at $37^{\circ} \mathrm{C}$, followed by the measurement of the amount of $\left[{ }^{3} \mathrm{H}\right]$ choline remained in the cells. Each point represents the mean \pm SEM $(n=3-4)$. ${ }^{*} p<0.05,{ }^{* *} p<0.001$ significantly different from control. 
Table I. Effects of various drugs on $\left[{ }^{3} \mathrm{H}\right]$ choline efflux from in vivo rat brain across the BBB

\begin{tabular}{lcccc}
\hline Compounds & $\begin{array}{c}\text { Concentration in the } \\
\text { injectate }(\mathrm{mM})\end{array}$ & $\begin{array}{c}\text { Concentration in the } \\
\text { brain }(\mathrm{mM})\end{array}$ & BEl (\%) & \% of control \\
\hline Control & 0 & 0 & $37.5 \pm 5.3$ & $(100)$ \\
+ hemicholinium-3 & 100 & 3.3 & $1.17 \pm 1.49$ & $(3)^{\mathrm{b}}$ \\
+ betaine & 100 & 3.3 & $33.2 \pm 2.1$ & $(89)$ \\
+ PBN & 10 & 0.33 & $17.1 \pm 1.1$ & $(46)^{\mathrm{a}}$ \\
+ acetyl L-carnitine & 100 & 3.3 & $25.7 \pm 4.4$ & $(69)$ \\
+ tacrine & 100 & 3.3 & $22.0 \pm 2.9$ & $(59)^{\mathrm{a}}$ \\
+ verapamil & 100 & 3.3 & $19.2 \pm 3.8$ & $(51)^{\mathrm{a}}$ \\
\hline
\end{tabular}

$\left[{ }^{3} \mathrm{H}\right]$ Choline $(80 \mathrm{nCi})$ and $\left[{ }^{14} \mathrm{C}\right]$ inulin $(4 \mathrm{nCi})$ dissolved in $0.5 \mu \mathrm{L}$ ECF buffer were injected into Par2 region of the brain in the presence of several compounds. The brain concentration was estimated from the injectate concentration divided by the dilution factor, i.e., 30.3, which was reported previously. Data, determined at 40 min after intracerebral microinjection, are mean $\pm \operatorname{SEM}(n=3)$.

${ }^{a} \mathrm{p}<0.05,{ }^{b} p<0.01$, significantly different from control.

PBN, $\alpha$-phenyl-n-tert-butyl nitrone

synthesis of acetylcholine in cerebrocortical prisms is due to its ability to diminish the efflux of endogenous choline from the nerve terminals. The decrease of choline efflux by tacrine at the BBB observed in the current study is consistent with this proposal. It means that the amount of choline near the abluminal membrane of capillary endothelium is increased by tacrine or donepezil hydrochloride. Therefore, we suggest that the inhibition of choline efflux from the brain at the BBB becomes one of the important strategies in raising brain acetylcholine level by enhancing the amount of choline in the brain. Betaine had no effect on the blood-to-brain choline efflux (Table I). GAT2/BGT-1, which is involved in GABA transport at the $B B B$ and betaine significantly inhibited $\left[{ }^{3} \mathrm{H}\right] \mathrm{GABA}$ uptake by TM-BBB cells (Takanaga et al., 2001). This result suggested that GAT2/BGT-1 had no correlation with choline efflux. Verapamil, which is a substrate of $p$ glycoprotein, inhibited choline efflux transport in rat brain (Table I). The substrates of p-glycoprotein include some of organic cations (Young et al., 2003). It is not known whether choline is substrate of $p$-glycoprotein or not, but choline transport at the BBB was inhibited by p-glycoprotein substrate. Therefore, further studies are needed to obtain the information on the relationship between choline transport and p-glycoprotein.

In conclusion, $A D$ therapeutics for example donepezil hydrochloride, tacrine and PBN inhibited brain-to-blood choline efflux transport at the BBB in vivo and in vitro. These findings suggest that other compounds structurally related to choline may also exhibit increased brain distribution via choline transport system and regulate choline level in the brain, leading to increase in acetylcholine synthesis.

\section{ACKNOWLEDGEMENTS}

This work was supported by the SRC Research Center for Women's Diseases of Sookmyung Women's University (2008). Also the authors wish to thank Dr. T. Terasaki for providing TR-BBB cell lines with kindness.

\section{REFERENCES}

Allen, D.D., and Smith, Q.R. (2001) Characterization of the blood-brain barrier choline transporter using the in situ rat brain perfusion technique. J. Neurochem. 76, 1032-1041.

Blusztajn, J.K., and Wurtman, R.J. (1983) Choline and cholinergic neurons. Science 221, 614-620.

Cohen, B.M., Renshaw, P.F., Stoll, A.L., Wurtman, R.J., Yurgelun-Todd, D., and Babb, S.M. (1995) Decreased brain choline uptake in older adults: an in vivo proton magnetic resonance spectroscopy study. J. Am. Med. Assoc. 274, 902907.

Cornford, E.M., Braun, L.D., and Oldendorf, W.H. (1978) Carrier mediated blood-brain barrier transport of choline and certain analogs. J. Neurochem. 30, 299-308.

Cornford, E.M. (1985) The blood-brain barrier, a dynamic regulatory interface. Mol. Physiol. 7, 219-259.

Dolezal, V., and Tucek, S. (1992) Investigation of the mechanism of the effect of tacrine (tetrahydroaminoacridine) on the metabolism of acetylcholine and choline in brain cortical prisms. J. Neural. Transm. Park. Dis. Dement. Sect. 4, 303318.

Grason, S.I. (1996) Evaluation of tacrine hydrochloride (Cognex) in two parallel-group studies. Acta. Neurol. Scand. Suppl. 165, 114-122.

Hosoya, K.I., Takashima, T., Tetsuka, K., Nagura, T., Ohtsuki, S., Takanaga, H., Ueda, M., Yanai, N., Obinata, M., and Terasaki, T. (2000) mRNA expression and transport characterization of conditionally immortalized rat brain capillary endothelial cell lines, a new in vitro BBB model for drug tar- 
geting. J. Drug Target. 8, 357-370.

Kakee, A., Terasaki, T., and Sugiyama, Y. (1996) Brain efflux index as a novel method of analyzing efflux transport at the blood-brain barrier. J. Pharmacol. Exp. Ther. 277, 1550-1559.

Kang, Y.S., Terasaki, T., Ohnishi, T., and Tsuji, A. (1990) In vivo and in vitro evidence for a common carrier mediated transport of choline and basic drugs through the blood-brain barrier. J. Pharmacobiodyn. 13, 353-360.

Kang, Y.S., Lee, K.E., Lee, N.Y., and Terasaki, T. (2005) Donepezil, tacrine and alpha-phenyl-n-tert-butyl nitrone (PBN) inhibit choline transport by conditionally immortalized rat brain capillary endothelial cell lines (TR-BBB). Arch. Pharm. Res. 28, 443-450.

Knapp, M.J., Knopman, D.S., Solomon, P.R., Pendlebury, W.W., Davis, C.S., and Gracon, S.I. (1994) A 30-week randomized controlled trial of high-dose tacrine in patients with Alzheimer's disease. J. Am. Med. Assoc. 271, 985-991.

Knecht, K.T., and Mason, R.P. (1993) In vivo spin trapping of xenobiotic free radical metabolites. Arch. Biochem. Biophys. 303, 185-194.

Lee, N.Y., and Kang, Y.S. (2006) In vivo brain-to-blood efflux transport of choline at the blood-brain barrier. J. Appl. Pharmacol. 14, 45-49.

MaNally, W.P., Pool, W.F., Sinz, M.W., Dehart, P., Ortwine, D.F., Huang, C.C., Chang, T., and Woolf, T.F. (1996) Distribution of tacrine and metabolites in rat brain and plasma after single- and multiple-dose regimens; Evidence for accumulation of tacrine in brain tissue. Drug Metab. Dispos. 24, 628633.

Matsui, K., Mishima, M., Nagai, Y., Yuzuriha, T., and Yoshimura, T. (1999) Absorption, Distribution, Metabolism, and Excretion of Donepezil (Aricept) after a Single Oral Administration to Rat. Drug Metab. Dispos. 27, 1406-1414.

Metting, T.L., Burgio, D.E., Terry, A.V., Beach, J.W., Mccurdy, C.R., and Allen, D.D. (1998) Inhibition of brain choline uptake by isoarecolone and lobeline derivatives: implications for potential vector-mediated brain drug delivery. Neurosci. Let. 258, 25-28.
Nitsch, R.M., Blusztajn, J.K., Pittas, A.G. Slack, B.E., Growdon, J.H., and Wurtman, R.J. (1992) Evidence for a membrane defect in Alzheimer disease brain. Proc. Natl. Acad. Sci. USA 89, 1671-1675.

Ohtsuki, S., and Terasaki T. (2007) Contribution of carrier-mediated transport systems to the blood-brain barrier as a supporting and protecting interface for the brain; importance for CNS drug discovery and development. Pharm. Res. 24, 1745-1758.

Pardridge, W.M. (1988) Recent advances in blood-brain barrier transport. Annu. Rev. Pharmacol. Toxicol. 28, 25-39.

Rho, J.P., and Lipson, L.G. (1997) Focus on donepezil: A reversible acetylcholinesterase inhibitor for the treatment of Alzheimer's disease. Formulary 32, 677-678.

Sawada, N., Takanaga, H., Matsuo, H., Naito, M., Tsuruo, T., and Sawada, Y. (1999) Choline uptake by mouse brain capillary endothelial cells in culture. J. Pharm. Pharmacol. 51, 847-852.

Smith, Q.R. (1993) Drug delivery to brain and the role of carriermediated transport. Adv. Exp. Med. Biol. 331, 83-93.

Spector, R. (1989) Micronutrient homeostasis in mammalian brain and cerebrospinal fluid. J. Neurochem. 53, 1667-1674.

Takada, Y., Vistica, D.T., Greig, N.H., Purdon, D., Rapoport, S.I., and Smith, Q.R. (1992) Rapid high affinity transport of a chemotherapeutic amino acid across the blood-brain barrier. Cancer Res. 52, 2191-2196.

Takanaga, H., Ohtsuki, S., Hosoya, K., and Terasaki, T. (2001) GAT2/BGT-1 as a system responsible for the transport of gamma-aminobutyric acid at the mouse blood-brain barrier. $J$. Cereb. Blood Flow Metabol. 21, 1232-1239.

Wurtman, R.J. (1992) Choline metabolism as a basis for the selective vulnerability of cholinergic neurons. Trends Neurosci. 15, 117-122.

Zhao, Q., Pahlmark, K., Smith, M.L., and Siesjo, B.K. (1994) Delayed treatment with the spin trap $\alpha$-phenyl-n-tert-butyl nitrone (PBN) reduces infarct size following transient middle cerebral artery occlusion in rats. Acta Physiol. Scand. 152, 349-350. 